\title{
La Medicina Del Futuro
}

$\begin{aligned} \text { Authors: } & \text { Ruben Villaverde } \\ \text { Submitted: } & \text { 1. March } 2016 \\ \text { Published: } & 1 \text {. March } 2016 \\ \text { Volume: } & 3 \\ \text { Issue: } & 1 \\ \text { Keywords: } & \text { Medicine, Future, Neuroscience, Quantum Physics, Art } \\ \text { DOI: } & 10.17160 / \text { josha.3.1.96 }\end{aligned}$

\section{TOSTArnal of Science, Humanities and Arts}




\title{
La Medicina Del Futuro
}

\section{Ruben Alejandro Villaverde, Mar del Plata, Argentina}

\author{
hermesathot@hotmail.com
}

Estamos en la Era de las Revoluciones Tecnológicas y Científicas más Grandes en toda la historia de la Humanidad. Hoy en casi la segunda Década del siglo XXI la Neurociencia nos asombra tanto como la Física Cuántica. Claro lo que está sucediendo es que la Medicina ya se parece más a un Arte y Ciencia que a la antigua y hasta nostálgica imagen de la medicina tradicional.

La Medicina la veo como un conjunto de otras ciencias que se influyen mutuamente, desde la notable Nanotecnología hasta la Ingeniería Genética se complementa con las innovaciones tecnológicas que van desde las fibras ópticas, los nanorobots, las cirugías por imágenes, la creación de órganos en 3D, son solo algunos ejemplos que nos muestra que estamos en el Umbral del Futuro de la Medicina.

Hoy en el año 2016 notamos que los avances en Medicina son realmente alucinantes, si bien creo que del mismo modo tendría que surgir dentro de la medicina un sentido Espiritual. Y aquí reside estimo lo que será el Futuro de la Medicina. Me interesa sobremanera la Bioenergética Medica con la inclusión del estudio de la Conciencia como del Inconsciente. En esta sentido la Neurociencia podrá aunar tanto al Psicoanálisis como a la propia Psicología. Pero aún asi me parece que para el estudio de la Mente, la misma Neurociencia tendrá que ser superada y/o ampliar sus fronteras a las regiones de lo ignoto.

Lo ignoto es el devenir, es percibir los planos inconexos de los bloques del futuro, los cuales poseen información de conocimientos. La Ciencia de la Mente será la continuación de las Neurociencia. Por el hecho de que estamos en las postrimerías de lo que se asoma del futuro, la Imagen del Superhombre. Esto está perfectamente pensado, ya que dado que todavía no ha aparecido un Einstein de la Neurociencia, es posible, que ya haya nacido.

Las investigaciones Médicas se abren en un amplísimo espectro, que cubre áreas como el de la células madres, pieles sintéticas, órganos 3D, Nanomedicina, Neurocognición, ingeniería genética en conjunto con la ingeniería cuántica informática. Esto abre un área que muy bien puede llamarse Medica Antropo-Cuántica. Es decir Estudiar la Nueva Imagen del Hombre que surge de estas Revoluciones Tecnológicas y Científicas.

Muy bien, ¿cómo veo el desarrollo de la medicina en conformación de intereses económicos políticos? Este es tema por demás interesante y muy apasionante. El del Marketing y la Medicina, la Publicidad Medica. Este se ve muy claro por medio de la Neuropolítica y Neuroética, como la Bioética. Ya el filósofo Michael Foucault nos habló mucho y muy bien en sus libros sobre Biopoder, Poder Psiquiátrico e Historia de la Clínica. Del mismo modo el filósofos Peter Sloterdijk tiene una Idea y Tesis realmente Original sobre lo que sería la evolución del hombre y de la humanidad acorde a los 
cambios biomédicos, desde las Esferas Placentarias Amnióticas hasta la Globalización Tecno-Bio-Medicas.

Sin duda que la Medicina desde la época esplendorosa de la Grecia Clásica hasta hoy nos ha acompañado con sus aciertos y sus fallas, como cualquier ciencia ya que es el hombre quien hace la ciencia, con nuestras propias falacias. Lo notable ha sido su propia Transformación desde la antigua Grecia, pasando por la Edad Media, el renacimiento, la llustración, hasta hoy. La Medicina que ha pasado por guerras nace permanentemente para ayudar al hombre a un Nuevo Alumbramiento y que esta sea más Espiritual.

Indudablemente ya estamos en el Umbral del Futuro y en la Era de la Inteligencia Artificial, que yo denomino Inteligencias Biospintrónica. Ya estamos en la era del Transhumanismo y muy próximos a la Singularidad Tecnológica. Vivimos sin duda épocas de cambios y modificaciones realmente asombrosas. Miremos pues con conciencia al Futuro de la Medicina. 